\title{
Research
}

\section{Delays in referral from primary care worsen survival for patients with colorectal cancer:}

\author{
a retrospective cohort study
}

\begin{abstract}
Background

Delays in referral for patients with colorectal cancer may occur if the presenting symptom is falsely attributed to a benign condition.

Aim

To investigate whether delays in referral from primary care are associated with a later stage of cancer at diagnosis and worse prognosis.
\end{abstract}

\section{Design and setting}

A national retrospective cohort study in England including adult patients with colorectal cancer identified from the cancer registry with linkage to Clinical Practice Research Datalink, who had been referred following presentation to their GP with a 'red flag' or 'non-specific' symptom.

\section{Method}

The hazard ratios (HR) of death were calculated for delays in referral of between 2 weeks and

3 months, and $>3$ months, compared with referrals within 2 weeks.

\section{Results}

A total of 4527 (63.5\%) patients with colon cancer and $2603(36.5 \%)$ patients with rectal cancer were included in the study. The percentage of patients presenting with redflag symptoms who experienced a delay of $>3$ months before referral was $16.9 \%$ of those with colon cancer and $13.5 \%$ of those with rectal cancer, compared with $35.7 \%$ of patients with colon cancer and $42.9 \%$ of patients with rectal cancer who presented with non-specific symptoms. Patients referred after 3 months with red-flag symptoms demonstrated a significantly worse prognosis than patients who were referred within 2 weeks (colon cancer: HR 1.53; $95 \%$ confidence interval $[\mathrm{Cl}]=1.29$ to 1.81; rectal cancer: HR 1.30; $95 \% \mathrm{Cl}=1.06$ to 1.60). This association was not seen for patients presenting with non-specific symptoms. Delays in referral were associated with a significantly higher proportion of late-stage cancers.

\section{Conclusion}

The first presentation to the GP provides a referral opportunity to identify the underlying cancer, which, if missed, is associated with a later stage in diagnosis and worse survival.

\section{Keywords}

cancer; colorectal cancer; delays; primary care referral: stage. survival.

\section{INTRODUCTION}

Delays in cancer diagnosis have been suggested as a possible cause for the laterstage and worse 1-year survival for patients with cancer in the UK compared with better performing Northern and Western European countries. ${ }^{1-3}$ In response, in 2000 the Department of Health and, more recently, the National Institute for Health and Care Excellence (NICE) issued referral guidelines for cancer based on the positive predictive value of particular symptoms, signs, or laboratory results. ${ }^{4}$ Although these guidelines have reduced the time to referra and diagnosis for cancer, ${ }^{5}$ the impact on prognosis is inconclusive. ${ }^{6-9}$

Most studies have analysed the entire pathway from primary care presentation to diagnosis, suggesting a waiting time paradox' of a shorter diagnostic interval being associated with a worse prognosis. In one of the few studies that have attempted to quantify the influence of the GP as a gatekeeper to secondary care, Tørring et al $l^{10}$ demonstrated an association between delay in primary care referral of up to 90 days and a later stage in colorectal cancer

The decision to refer is multifactorial. A GP may carry out investigations and manage the patient in the community for a presumed non-cancerous condition ${ }^{11}$ because the symptoms for benign and malignant colorectal conditions are similar, ${ }^{12}$ with low positive predictive

CS Arhi, PhD, FRCS, clinical research fellow; EM Burns, PhD, FRCS, clinical lecturer; G Bouras $\mathrm{PhD}$, FRCS, clinical research fellow; $\mathbf{P}$ Ziprin, FRCS, consultant surgeon; A Darzi, KBE, MD FRCS, professor of surgery, Department of Surgery and Cancer, Imperial College London, London. A Bottle, PhD, MFPH, FHEA, reader in medical statistics; $\mathbf{P}$ Aylin, FRCPE, FPH, professor in epidemiology and public health, School of Public Health, Imperial College London, London. Address for correspondence Chanpreet Arhi, Imperial College London, values. ${ }^{13}$ However, an increased propensity to use the urgent referral pathway has been associated with an improved prognosis, suggesting a low threshold for referral has the potential to improve patient outcome..$^{14}$

Using a large database of primary care records of patients in England, this study aimed to describe the proportion of patients with colorectal cancer who experienced delays in referral, and investigate whether such delays are associated with a worse prognosis, while taking into account the presenting symptom.

\section{METHOD}

\section{Data source}

Routine electronic primary care medical records were provided by the Clinical Practice Research Datalink (CPRD) (data protocol: 15_247), a database that covers approximately $6.9 \%$ of the UK population. ${ }^{15}$ As was carried out for this study, it is possible to link the CPRD data at an individual patient level to the cancer registry, cause of death from the Office for National Statistics, and secondary care episodes from Hospital Episode Statistics (HES).'

\section{Patient inclusion criteria}

Patients were included if they were aged $>18$ years, had a colorectal cancer diagnosis International Classification of Diseases 10th Revision [ICD-10] codes C18, C19 for colon, $\mathrm{C} 20$ for rectal) in the cancer registry between 2000 and 2013, had been referred
Department of Surgery and Cancer, St Mary's Hospital Campus, Praed Street, London W2 1NY, UK.

Email: c.arhidimperial.ac.uk

Submitted: 4 August 2019; Editor's response: 14 October 2019; final acceptance: 16 January 2020.

OBritish Journal of General Practice

This is the full-length article (published online 16 Jun 2020) of an abridged version published in print. Cite this version as: $\mathbf{B r} \mathbf{J}$ Gen Pract 2020; DOI: https://doi.org/10.3399/bjgp20X710441 


\section{How this fits in}

National referral guidelines have reduced the interval to referral for patients with suspected cancer, but it remains unclear whether this equates to an improvement in survival. This study demonstrates that delays in referral from primary care are associated with a worse prognosis for patients with colorectal cancer, particularly if they initially present with red-flag symptoms such as rectal bleeding.

to secondary care, and had presented to the GP in the year leading up to referral with a relevant symptom. Patients diagnosed as an emergency, death certificate only, or screening were excluded because it is unclear whether such patients would have been seen by their GP before diagnosis. Patients with a preceding cancer diagnosis in any of the datasets before the colorectal cancer diagnosis were excluded, because GPs would likely have been more aware of a potential cancer diagnosis in such patients. Colon and rectal cancer were analysed separately.

The Charlson score, a weighted composite score of comorbidities, was calculated from 3 years of CPRD and HES data preceding the cancer diagnosis using updated codes from previous studies. ${ }^{17,18}$ Socioeconomic deprivation quintiles, based on the Index of Multiple Deprivation (IMD), was provided by CPRD. Age was taken at the time of cancer diagnosis.

\section{Definition of diagnostic route}

For patients diagnosed from 2006 onwards, the cancer registry provided the route to diagnosis' as per the algorithm described by Elliss-Brookes et al. ${ }^{19}$

For cancer registrations preceding this, patients with an emergency HES admission containing an ICD-10 code for colorectal cancer in the 6 months before the cancer registry diagnosis date were deemed to have been diagnosed as an emergency and so were excluded. If $>1$ HES episode was present, then the admission nearest to the diagnosis date was used as the relevant diagnostic episode.

\section{Definition of referral}

See Supplementary Table S1 for details of codes for 'relevant referral'. Generic referral codes such as 'referral for further care', 'referral to general medical clinic', and 'referred by GP' were excluded, because it was unclear whether these were related to a suspicion of cancer.

\section{Definition of presenting symptom}

Read codes for red-flag symptoms (rectal bleeding, anaemia, abdominal mass, diarrhoea, and change in bowel habit) or nonspecific labdominal pain, constipation, other bowel function, weight loss, and fatiguel were based on previous studies ${ }^{20,21}$ (details can be provided by the authors on request), and were reviewed independently for inclusion by two authors. Disagreements were resolved after discussion. All patients presenting with rectal bleeding alone or in combination with any other symptoms were included as one group. This was repeated stepwise for each of the symptoms in the order above, so each patient was represented once in the analysis.

\section{Definition of intervals before diagnosis and delays}

The intervals leading up to diagnosis were based on the Aarhus statement. ${ }^{22}$ The primary care interval was defined from first presentation to referral and the hospital interval from referral to diagnosis. In a national audit, up to $90 \%$ of patients with colorectal cancer were referred within 3 months, ${ }^{23}$ whereas two consultations before referral was associated with a median of 2 weeks. ${ }^{24}$ Therefore the primary care interval was split into three groups: within 2 weeks, 2 weeks to 3 months, and $>3$ months.

\section{Statistical analysis}

Differences in presenting symptoms according to age $<<50,50-59,60-69,70-79$, $\geq 80$ ), sex, IMD (level of deprivation from 1 to 5), and Charlson score $(0,1,>1)$ were investigated. The referral and hospital interval and stage (I-IV and missing) according to presenting symptom are described.

\section{Survival analysis}

Survival was measured from date of cancer diagnosis in the cancer registry to allcause mortality. Cox proportional hazards modelling described the hazard ratio (HR) for each presenting symptom, with rectal bleeding as the reference category, while adjusting for sex, age, Charlson score, and IMD. This was repeated after including only patients referred within 2 weeks, to negate the effect of a delay in referral. To determine survival for those referred between 2 weeks and 3 months, and $>3$ months compared with those referred within 2 weeks for each symptom, a similar model was used while taking into account the interval from referral to diagnosis as a continuous independent variable. None of the independent variables violated the proportional hazards assumption. 
Table 1. Frequency of colon and rectal cancer and stage at diagnosis for each presenting symptom

\begin{tabular}{|c|c|c|c|c|c|c|c|c|c|c|c|c|}
\hline \multirow[b]{3}{*}{ Presenting symptom } & \multicolumn{6}{|c|}{ Colon cancer } & \multicolumn{6}{|c|}{ Rectal cancer } \\
\hline & \multirow{2}{*}{$\begin{array}{c}\text { Frequency } \\
n(\%)\end{array}$} & \multicolumn{4}{|c|}{ Stage (\% per symptom) } & \multirow[b]{2}{*}{ Missing } & \multirow{2}{*}{$\begin{array}{c}\text { Frequency } \\
n(\%)\end{array}$} & \multicolumn{5}{|c|}{ Stage (\% per symptom) } \\
\hline & & I & II & III & IV & & & I & II & III & IV & Missing \\
\hline Red flag & 2725 (60.2) & 14.4 & 31.3 & 27.0 & 9.8 & 17.5 & 2004 (77.0) & 17.3 & 21.5 & 27.5 & 10.5 & 23.3 \\
\hline Non-specific & 1802 (39.8) & 6.4 & 31.0 & 27.2 & 16.5 & 18.8 & $599(23.0)$ & 14.9 & 18.7 & 23.9 & 12.4 & 30.2 \\
\hline Rectal bleeding & $924(20.4)$ & 21.3 & 26.2 & 26.9 & 8.0 & 17.5 & $1069(41.1)$ & 20.5 & 20.5 & 28.5 & 8.4 & 22.1 \\
\hline Anaemia & $844(18.6)$ & 9.8 & 37.0 & 28.4 & 9.0 & 15.8 & $110(4.2)$ & 17.3 & 30.9 & 17.3 & 6.4 & 28.2 \\
\hline Change in bowel habit & 461 (10.2) & 11.5 & 30.2 & 27.8 & 11.3 & 19.3 & $442(17.0)$ & 15.6 & 23.1 & 27.8 & 13.3 & 20.1 \\
\hline Diarrhoea & $448(9.9)$ & 12.5 & 32.6 & 25.7 & 12.9 & 16.3 & 369 (14.2) & 10.3 & 19.5 & 26.8 & 14.4 & 29.0 \\
\hline Abdominal mass & $48(1.1)$ & 6.3 & 29.2 & 8.3 & 16.7 & 39.6 & $14(0.5)$ & 7.1 & 28.6 & 35.7 & 7.1 & 21.4 \\
\hline Abdominal pain & 1053 (23.3) & 6.5 & 30.7 & 28.8 & 17.9 & 16.1 & $212(8.1)$ & 10.8 & 21.7 & 28.3 & 10.4 & 28.8 \\
\hline Constipation & $307(6.8)$ & 6.8 & 30.3 & 28.3 & 12.1 & 22.5 & $216(8.3)$ & 15.7 & 15.7 & 22.7 & 14.4 & 31.5 \\
\hline Other bowel function & $96(2.1)$ & 7.3 & 37.5 & 24.0 & 12.5 & 18.8 & $67(2.6)$ & 11.9 & 22.4 & 20.9 & 14.9 & 29.9 \\
\hline Weight loss or fatigue & $346(7.6)$ & 5.8 & 30.9 & 22.5 & 17.3 & 23.4 & $104(4.0)$ & 23.1 & 16.3 & 19.2 & 10.6 & 30.8 \\
\hline All & 4527 (100) & 11.2 & 31.2 & 27.1 & 12.5 & 18.0 & 2603 (100) & 16.7 & 20.9 & 26.7 & 10.9 & 24.9 \\
\hline
\end{tabular}

The Pearson $\chi^{2}$ test compared categorical data, whereas the Kruskal-Wallis test was used for comparison of non-parametric data such as intervals. Generalised estimating equation modelling provided robust confidence intervals to account for clustering within practices. ${ }^{25}$ Statistical significance was taken at $P<0.05$. All analysis was undertaken using IBM SPSS Statistics (version 24)

\section{RESULTS}

Between 2000 and 2013, 14103 patients were diagnosed with a colorectal cancer as a non-emergency, of whom 7130 had a referral and a relevant symptom recorded in CPRD, split into 4527 (63.5\%) colon and $2603(36.5 \%)$ rectal cancer cases (see Supplementary Figure S1 for details of excluded patients). In the rectal cancer group, there was a higher percentage of male, younger age, fewer comorbidities, and earlier stage cancer compared with the colon cancer group (see Supplementary Table S2 for details of patient demographics).

\section{Presenting symptom according to patient demographics}

Abdominal pain (23.3\%) and per rectal bleeding (41.1\%) were the two most common presenting symptoms for colon and rectal cancer, respectively, with redflag symptoms more common than nonspecific symptoms (Table 1).

\section{Intervals along the patient pathway}

For all patients with colorectal cancer, the median primary care interval was 9 days (interquartile range [IQR] $0-77$ ) and the hospital interval was 42 days (IQR 20-83). For patients with both colon and rectal cancer the median primary care interval for rectal bleeding, change in bowel habit, or those noted to have an abdominal mass was 1 day. All other symptoms were associated with a significantly longer primary care interval compared with rectal bleeding, in particular, constipation for colon cancer (median 75 days; IQR 16-209) and weight loss/fatigue for rectal cancer (median 100 days; IQR 21.25-213.5).

For colon cancer, only a change in bowel habit (median 41 days; IQR 22-75) or an abdominal mass (median 30.5 days; IQR 15-53.5) at presentation significantly decreased the hospital interval compared with rectal bleeding (median 50 days; IQR 23-91). For rectal cancer, no symptom was associated with a decrease in the hospital interval compared with rectal bleeding (median 29 days; IQR 14-62). Patients with colon cancer who had anaemia (median 55 days; IQR 28-99) and patients with rectal cancer who had abdominal pain (median 42.5 days; IQR 17-88) or weight loss/ fatigue (median 38 days; IQR 19.5-83.75) demonstrated a significantly increased hospital interval compared with those who had rectal bleeding.

Patients with colon cancer who had non-specific symptoms had a significantly longer referral compared with those who had red-flag symptoms (median 42 days; IQR 8-160.25 versus 4 days; IQR 0-40), although no difference was seen in the hospital interval. For patients with rectal 


\section{Table 2. Adjusted hazard ratio of death for patients with colon cancer according to interval to referral}

\begin{tabular}{|c|c|c|c|c|}
\hline Symptom & $\begin{array}{l}\text { Referral } \\
\text { interval }^{\mathrm{a}}\end{array}$ & $n(\%)$ & $\begin{array}{l}\text { Median hospital } \\
\text { interval (IQR) }\end{array}$ & $\begin{array}{l}\text { Hazard ratio } \\
\text { (95\% Cl) }\end{array}$ \\
\hline \multirow[t]{3}{*}{ Red flag } & I & $1739(63.8)$ & $45(23-85)$ & ref \\
\hline & $\|$ & 526 (19.3) & $49.5(25-85)$ & $1.28(1.09 \text { to } 1.51)^{\mathrm{b}}$ \\
\hline & III & 460 (16.9) & $60.5(28-118.5)^{c}$ & $1.53(1.29 \text { to } 1.81)^{c}$ \\
\hline \multirow[t]{3}{*}{ Non-specific } & । & 582 (32.3) & 44 (22-85.25) & ref \\
\hline & $\|$ & 576 (32.0) & $49(25-89)$ & 0.94 (0.79 to 1.12 ) \\
\hline & III & 644 (35.7) & $57(28-113)^{c}$ & 0.85 (0.72 to 1.01$)$ \\
\hline \multirow[t]{3}{*}{ Rectal bleeding } & I & 704 (76.2) & 45 (22-90.75) & ref \\
\hline & $\|$ & $116(12.6)$ & $51.5(24.5-91.5)$ & 1.34 (0.93 to 1.93 ) \\
\hline & III & 104 (11.3) & $64.5(37-104.25)^{b}$ & $1.84(1.29 \text { to } 2.63)^{\mathrm{b}}$ \\
\hline \multirow[t]{3}{*}{ Anaemia } & । & 488 (51.7) & $49.5(26.25-90)$ & ref \\
\hline & $\|$ & 259 (27.4) & 61 (33-98) & $1.27(1.05 \text { to } 1.72)^{d}$ \\
\hline & III & 197 (20.9) & $62(30.5-128)^{d}$ & $1.70(1.30 \text { to } 2.23)^{c}$ \\
\hline \multirow[t]{3}{*}{ Change in bowel habit } & । & 347 (75.3) & $42(22-77)$ & ref \\
\hline & $\|$ & 87 (18.9) & $38(24-71)$ & 1.14 (0.77 to 1.70$)$ \\
\hline & III & $27(5.9)$ & 38 (23-83) & 0.99 (0.48 to 2.06) \\
\hline \multirow[t]{3}{*}{ Diarrhoea } & । & 161 (35.9) & $43(22-83.5)$ & ref \\
\hline & $\|$ & 159 (35.5) & 48 (23-82) & 1.01 (0.71 to 1.42 ) \\
\hline & III & $128(28.6)$ & 57 (24.25-134.75) & 1.06 (0.73 to 1.53 ) \\
\hline \multirow[t]{3}{*}{ Abdominal pain } & । & 369 (35.0) & 43 (21.5-83) & ref \\
\hline & $\|$ & 358 (34.0) & 49 (25-87.5) & 0.92 (0.74 to 1.15 ) \\
\hline & III & $326(31.0)$ & $57(27.75-115.5)^{b}$ & $0.76(0.59 \text { to } 0.95)^{d}$ \\
\hline \multirow[t]{3}{*}{ Constipation } & । & $74(24.1)$ & 35 (15-87.5) & ref \\
\hline & $\|$ & 90 (29.3) & 46.5 (22-89) & 1.01 (0.61 to 1.65 ) \\
\hline & III & $143(46.6)$ & $55(28-129)^{d}$ & 0.97 (0.62 to 1.53) \\
\hline \multirow[t]{3}{*}{ Weight loss or fatigue } & । & 125 (36.1) & 49 (22.5-91.5) & ref \\
\hline & $\|$ & $92(26.6)$ & 56 (27-100.75) & 0.98 (0.67 to 1.45$)$ \\
\hline & III & 129 (37.3) & $61(25.5-104.5)$ & $0.97(0.67$ to 1.41$)$ \\
\hline \multirow[t]{3}{*}{ All patients } & 1 & 2321 (51.3) & 45 (23-85) & ref \\
\hline & $\|$ & 1102 (24.3) & 49 (25-87) & $1.28(1.14 \text { to } 1.44)^{c}$ \\
\hline & III & $1104(24.4)$ & $58.5(28-114.75)^{c}$ & $1.31(1.16 \text { to } 1.47)^{c}$ \\
\hline
\end{tabular}

alnterval I =<2 weeks. Interval II = 2 weeks to 3 months. Interval III = > 3 months. Hazard ratio adjusted for age sex, Charlson score, Index of Multiple Deprivation, and interval from referral to diagnosis. ${ }^{b} 0.005$ to $<0.05,{ }^{c} 0.0005$ to $<0.005,{ }^{d}<0.0005$. Data for 'other bowel function' and 'abdominal mass' not shown as too few cases of each to carry out analysis. $I Q R=$ interquartile range. patients with rectal cancer and $13.5 \%$ of those with red-flag symptoms experienced a delay of $>3$ months before referral, which increased to $42.9 \%$ of those presenting with non-specific symptoms (Table 3 ).

\section{Change in hospital interval following a delay in referral}

For colon cancer, a referral delay of between 2 weeks and 3 months did not significantly delay the hospital interval compared with referrals within 2 weeks (Table 2). However, patients who were referred after 3 months demonstrated a significantly longer hospital interval if rectal bleeding, anaemia, abdominal pain, or constipation were the presenting symptoms. For rectal cancer, only delays of $>3$ months for a change in bowel habit or diarrhoea significantly increased the hospital interval by a median of 22 and 15 days, respectively (Table 3 ).

\section{Stage at diagnosis and hazard ratio of} death according to presenting symptom

Patients presenting with rectal bleeding had the highest proportion of stage I disease for both sites (colon: $21.3 \%$; rectal: $20.5 \%$ ) (Table 1). Consequently, red flag symptoms as a group had a higher proportion of stage I disease for both sites.

All presenting symptoms were associated with a worse prognosis compared with rectal bleeding, which reflected the lower proportion of patients with stage III or IV cancer in the latter with rectal bleeding (Tables 1 and 4). When grouped together, patients with colon or rectal cancer who had non-specific symptoms had a worse outcome than those with redflag symptoms (colon cancer: HR 1.49; $95 \%$ confidence interval $[\mathrm{Cl}]=1.36$ to 1.64 ; rectal cancer: $\mathrm{HR} 1.45 ; 95 \% \mathrm{Cl}=1.26$ to 1.67) (Table 4). After excluding patients who would have experienced a delay in referral of $>2$ weeks, the HR relative to rectal bleeding significantly increased for all symptoms, except for "other bowel function'.

\section{Delays in referral and prognosis}

Overall, delays in referral of between 2 weeks and 3 months (HR 1.28; 95\% $\mathrm{Cl}=1.14$ to 1.44 ) and of $>3$ months (HR $1.31 ; 95 \% \mathrm{Cl}=1.16$ to 1.47 ) for patients with colon cancer were associated with a worse prognosis compared with referrals within 2 weeks (Table 2), but only delays of 2 weeks to 3 months (HR 1.33; $95 \% \mathrm{Cl}=1.13$ to 1.55 ) were associated with a worse prognosis for patients with rectal cancer (Table 3).

Patients with colon cancer who had rectal bleeding who experienced a delay in primary care of $>3$ months (HR 1.84; $95 \% \mathrm{Cl}=1.29$ 


\begin{tabular}{|c|c|c|c|c|}
\hline Symptom & $\begin{array}{l}\text { Referral } \\
\text { interval }^{\text {a }}\end{array}$ & $n(\%)$ & $\begin{array}{c}\text { Median hospital } \\
\text { interval (IQR) }\end{array}$ & $\begin{array}{l}\text { Hazard ratio } \\
\qquad(95 \% \mathrm{Cl})\end{array}$ \\
\hline Red flag & $\begin{array}{l}\text { I } \\
\text { II } \\
\text { III }\end{array}$ & $\begin{array}{l}1414 \text { (70.6) } \\
319(15.9) \\
271(13.5)\end{array}$ & $\begin{array}{l}27(14-58.25) \\
27(14-59) \\
40(20-78)^{b}\end{array}$ & $\begin{array}{c}\text { ref } \\
1.11(0.90 \text { to } 1.36) \\
1.30(1.06 \text { to } 1.60)^{c}\end{array}$ \\
\hline Non-specific & $\begin{array}{l}\text { I } \\
\text { II } \\
\text { III }\end{array}$ & $\begin{array}{l}153(25.5) \\
189(31.6) \\
257(42.9)\end{array}$ & $\begin{array}{l}29(14-77.5) \\
37(18.5-61) \\
43(17.5-87)^{b}\end{array}$ & $\begin{array}{c}\text { ref } \\
1.14(0.85 \text { to } 1.54) \\
0.57(0.42 \text { to } 0.78)^{b}\end{array}$ \\
\hline Rectal bleeding & $\begin{array}{l}\text { I } \\
\text { II } \\
\text { III }\end{array}$ & $\begin{array}{c}848(79.3) \\
121(11.3) \\
100(9.4)\end{array}$ & $\begin{array}{c}28(14-61) \\
29(15.5-57.5) \\
36.5(19.25-69.75)\end{array}$ & $\begin{array}{c}\text { ref } \\
1.01(0.71 \text { to } 1.45) \\
1.65(1.18 \text { to } 2.31)^{d}\end{array}$ \\
\hline Anaemia & $\begin{array}{l}\text { । } \\
\text { II } \\
\text { III }\end{array}$ & $\begin{array}{l}54(49.1) \\
26(23.6) \\
30(27.3)\end{array}$ & $\begin{array}{c}32.5(18-61) \\
27.5(14-60) \\
44.5(15.25-91.5)\end{array}$ & $\begin{array}{c}\text { ref } \\
0.73 \text { (0.33 to } 1.63) \\
0.77 \text { (0.34 to } 1.76)\end{array}$ \\
\hline Change in bowel habit & $\begin{array}{l}\text { I } \\
\text { II } \\
\text { III }\end{array}$ & $\begin{array}{c}348(78.7) \\
57(12.9) \\
37(8.4)\end{array}$ & $\begin{array}{c}24(13-49) \\
26(13.5-58) \\
46(26-106)^{d}\end{array}$ & $\begin{array}{c}\text { ref } \\
0.79(0.49 \text { to } 1.29) \\
0.78 \text { (0.41 to } 1.72)\end{array}$ \\
\hline Diarrhoea & $\begin{array}{l}\text { । } \\
\text { II } \\
\text { III }\end{array}$ & $\begin{array}{l}155(42.0) \\
113(30.6) \\
101(27.4)\end{array}$ & $\begin{array}{l}27(14-63) \\
24(13-65) \\
42(21-80)^{c}\end{array}$ & $\begin{array}{c}\text { ref } \\
1.30(0.90 \text { to } 1.89) \\
1.13(0.77 \text { to } 1.67)\end{array}$ \\
\hline Abdominal pain & $\begin{array}{l}\text { I } \\
\text { II } \\
\text { III }\end{array}$ & $\begin{array}{l}68(32.1) \\
61(28.8) \\
83(39.2)\end{array}$ & $\begin{array}{c}42.5(16.25-84) \\
41(18-83.5) \\
49(17-107)\end{array}$ & $\begin{array}{c}\text { ref } \\
1.19(0.72 \text { to } 1.98) \\
0.57(0.33 \text { to } 1.00)^{c}\end{array}$ \\
\hline Constipation & $\begin{array}{l}\text { । } \\
\text { II } \\
\text { III }\end{array}$ & $\begin{array}{l}51(23.6) \\
75(34.7) \\
90(41.7)\end{array}$ & $\begin{array}{c}42.5 \text { (16.25-84) } \\
41 \text { (18-83.5) } \\
49 \text { (17-107) }\end{array}$ & $\begin{array}{c}\text { ref } \\
1.29(0.77 \text { to } 2.14) \\
0.68(0.40 \text { to } 1.17)\end{array}$ \\
\hline Weight loss or fatigue & $\begin{array}{c}\text { । } \\
\text { II } \\
\text { III }\end{array}$ & $\begin{array}{l}22(21.2) \\
26(25.0) \\
56(53.8)\end{array}$ & $\begin{array}{c}32(16.25-85) \\
37(16.5-73.5) \\
43.5(21.25-93.25)\end{array}$ & $\begin{array}{c}\text { ref } \\
1.05(0.45 \text { to } 2.41) \\
0.37(0.18 \text { to } 0.78)^{d}\end{array}$ \\
\hline All patients & $\begin{array}{l}\text { I } \\
\text { II } \\
\text { III }\end{array}$ & $\begin{array}{l}1567(60.2) \\
508(19.5) \\
528(20.3)\end{array}$ & $\begin{array}{c}27(14-60) \\
31(14-59.75) \\
42(19-84)^{b}\end{array}$ & $\begin{array}{c}\text { ref } \\
1.33(1.13 \text { to } 1.55)^{\mathrm{b}} \\
1.08(0.92 \text { to } 1.27)\end{array}$ \\
\hline \multicolumn{5}{|c|}{$\begin{array}{l}\text { Interval I }=<2 \text { weeks. Interval II = } 2 \text { weeks to } 3 \text { months. Interval III = > } 3 \text { months. Hazard ratio adjusted for age, } \\
\text { sex, Charlson score, Index of Multiple Deprivation, and interval from referral to diagnosis. }{ }^{b} 0.005 \text { to }<0.05,{ }^{c} 0.0005 \text { to } \\
<0.005,{ }^{d}<0.0005 . \text { Data for 'other bowel function' and 'abdominal mass' not shown as too few cases of each to carry } \\
\text { out analysis. IQR = interquartile range. }\end{array}$} \\
\hline
\end{tabular}

to 2.63) demonstrated a significantly worse prognosis compared with patients with rectal bleeding who were referred within 2 weeks (Table 2). This corresponds to an increase in stage III and IV cancer in the longest interval group. Although a similar trend was seen for patients who were referred between 2 weeks and 3 months, this did not reach significance. Patients with colon cancer who had red-flag symptoms demonstrated an increase in HR for both those who were referred between 2 weeks and 3 months (HR 1.28; $95 \% \mathrm{Cl}=1.09$ to 1.51) and $>3$ months (HR 1.53; $95 \% \mathrm{Cl}=1.29$ to 1.81) (Table 2), with a concomitant rise in late stage at diagnosis (from $8.2 \%$ stage IV with referral within 2 weeks, $11.4 \%$ for those referred between 2 weeks and 3 months, to $14.1 \%$ in the $>3$ month referral group). A similar finding was noted in the subgroup analysis of patients with colon cancer who had anaemia (Table 2).

Patients with rectal cancer who had rectal bleeding also had a worse prognosis ( HR 1.65; $95 \% \mathrm{Cl}=1.18$ to 2.31$)$ if referral was delayed to $>3$ months (Table 3 ), which corresponded to a decrease in stage I from $22.1 \%$ to $12.0 \%$, and an increase in missing stage from $21.8 \%$ to $26.0 \%$ (data not shown). Again, patients with red-flag symptoms and a delay of $>3$ months had a worse prognosis (HR 1.30; $95 \% \mathrm{Cl}=1.06$ to 1.60) compared with those referred within 2 weeks (Table 3).

There was no difference in outcome if patients with either colon or rectal cancer had experienced a delay with the other symptoms. 
Table 4. Hazard ratio of death $(95 \% \mathrm{Cl})$ for patients with colon and rectal cancer according to presenting symptom compared with either red-flag symptoms as a group or rectal bleeding only

\begin{tabular}{|c|c|c|c|c|}
\hline \multirow[b]{2}{*}{$\begin{array}{l}\text { Presenting } \\
\text { symptom }\end{array}$} & \multicolumn{2}{|c|}{ Colon cancer } & \multicolumn{2}{|c|}{ Rectal cancer } \\
\hline & All patients & $\begin{array}{l}\text { Referral within } \\
2 \text { weeks only }\end{array}$ & All patients & $\begin{array}{l}\text { Referral within } \\
2 \text { weeks only }\end{array}$ \\
\hline Red flag & ref & ref & ref & ref \\
\hline Non-specific & $1.49(1.36 \text { to } 1.64)^{a}$ & $1.84(1.59 \text { to } 2.14)^{a}$ & $1.45(1.26 \text { to } 1.67)^{a}$ & $1.81(1.42 \text { to } 2.31)^{a}$ \\
\hline Rectal bleeding & ref & ref & ref & ref \\
\hline Anaemia & $1.40(1.18 \text { to } 1.67)^{a}$ & $1.36(1.08 \text { to } 1.70)^{\mathrm{b}}$ & 1.30 (0.94 to 1.78 ) & 1.92 (1.28 to 2.87)a \\
\hline Change in bowel habit & $1.33(1.08 \text { to } 1.62)^{a}$ & $1.48(1.16 \text { to } 1.88)^{b}$ & $1.34(1.11 \text { to } 1.61)^{b}$ & $1.53(1.25 \text { to } 1.89)^{a}$ \\
\hline Diarrhoea & $1.72(1.41 \text { to } 2.08)^{a}$ & $1.95(1.47 \text { to } 2.58)^{\mathrm{a}}$ & $1.68(1.39 \text { to } 2.03)^{\mathrm{a}}$ & $1.63(1.23 \text { to } 2.15)^{\mathrm{a}}$ \\
\hline Abdominal mass & $3.99(2.75 \text { to } 5.78)^{a}$ & $4.60(3.05 \text { to } 6.95)^{a}$ & 1.92 (0.90 to 4.06$)$ & $3.10(1.24 \text { to } 7.30)^{a}$ \\
\hline Abdominal pain & $2.00(1.71 \text { to } 2.34)^{a}$ & $2.51(2.03 \text { to } 3.11)^{a}$ & $1.53(1.21 \text { to } 1.93)^{\mathrm{a}}$ & $1.83(1.26 \text { to } 2.66)^{a}$ \\
\hline Constipation & $1.70(1.36 \text { to } 2.11)^{a}$ & $1.90(1.28 \text { to } 2.83)^{a}$ & $1.87(1.49 \text { to } 2.34)^{b}$ & $2.61(1.73 \text { to } 3.94)^{\mathrm{a}}$ \\
\hline Other bowel function & $1.45(1.01 \text { to } 2.09)^{c}$ & 1.67 (0.68 to 4.08) & $1.61(1.10 \text { to } 2.38)^{c}$ & 1.74 (0.72 to 4.22) \\
\hline Weight loss or fatigue & 2.38 (1.95 to 2.90$)^{a}$ & $2.76(2.05 \text { to } 3.72)^{a}$ & $1.69(1.24 \text { to } 2.29)^{\mathrm{b}}$ & 3.55 (2.07 to 6.09) \\
\hline
\end{tabular}

\section{DISCUSSION}

\section{Summary}

A delay in referral for patients with colon or rectal cancer with red-flag symptoms, particularly rectal bleeding, was associated with a later stage at diagnosis and a worse prognosis. In addition, compared with patients who present with rectal bleeding, prognosis is worse for patients who present with other cancer-associated symptoms, even after exclusion of patients who experienced a delay in referral of $>2$ weeks. Although a patient may have experienced a referral delay of $>3$ months, the hospital interval was lengthened by a median of only 13 days, indicating the primary care interval has a greater influence on diagnostic delays than the hospital interval.

\section{Strengths and limitations}

This study included a large number of patients, with a varied set of symptoms, from a data source that has been shown to be representative of the national population. ${ }^{26}$ The data are not liable to recall bias because the clinical information was recorded at the time of consultation. The finding that delays in primary care are associated with a worse prognosis is reflected by a later tumour stage. This supports the theory that delays lead to a progression of disease. To the authors' knowledge, this is also the first study to describe the hospital interval for individual symptoms associated with colorectal cancer.
As CPRD data are collected routinely, there are potential issues with missing data. It is not possible to determine the duration of symptoms before the patient presented to the GP, which could have influenced the promptness of referral..$^{27}$ The effect of delays for patients with the same presenting symptom were compared to minimise the impact of these missing data. The recording of $>1$ symptom at presentation was poor (data not shown), indicating the GP was using a combination of Read codes and free text, and perhaps recording the symptom related to referral as a Read code. ${ }^{28}$ It is not possible to determine with certainty that the symptom recorded was caused by cancer, although this is an issue with any study that describes the symptoms before diagnosis. This may explain the finding that delays with abdominal pain were associated with an improved outcome because the initial presentation may not have been cancer related. The non-significant findings regarding stage and delays for most of the patients with non-specific symptoms may reflect a lack of power for these subsets. Stage data were missing for $20 \%$ of all patients. As missing stage is associated with a death soon after diagnosis, previous studies have amalgamated this category with stage III and IV. However, such simplification will fail to differentiate those cases with poor registry input and earlystage cancer.

Other possible confounders such as smoking history and chemotherapy 
treatment were not included because these were not robustly recorded in CPRD or linked datasets. Although missing data have the potential to introduce bias, no national dataset currently exists that provides better coverage while including the prepresentation interval.

\section{Comparison with existing literature}

This findings of this study correspond to those of Tørring et a $l^{10}$ that delays in primary care are associated with a worse prognosis, although they used stage rather than mortality as the primary outcome. However, their findings were only significant for one of the six datasets used when analysed individually, they included emergency patients, and they did not stratify according to presenting symptom. Excluding emergency patients from the current study potentially reduced the effect of confounding by indication. Most studies have analysed the difference between urgent and routine referral pathways, showing no significant difference in stage or survival between the two routes. ${ }^{8,29,30} \mathrm{~A}$ national audit in England based on primary care data described the median primary care interval, irrespective of the presenting symptom, as 7 days for patients with colorectal cancer, which is similar to the current study's finding of 9 days, although the IQR of the audit was narrower (0-33 days). ${ }^{24}$

Most studies have concentrated on the interval from onset of symptoms to diagnosis or treatment. In a 2015 systematic review, Neal et al ${ }^{13}$ stated it was difficult to make conclusions about which intervals were important leading up to diagnosis because there were differences in design. Delays leading to worse outcome have been described for rectal ${ }^{32}$ and colorectal cancer, ${ }^{33}$ although most studies have found no association between delays and outcome ${ }^{34-38}$ or stage. ${ }^{39,40}$ More recent studies have shown that short intervals were associated with a worse outcome, presumably as a result of more aggressive cancers. ${ }^{33,41,42}$ In the current study, delays in referral with non-specific symptoms, such as abdominal pain, were associated with a better stage and prognosis.

Patients with red-flag symptoms experienced the shortest interval before referral, reflecting the national referral guidelines from NICE. ${ }^{5.43}$ The current study confirms that patients with per rectal bleeding are diagnosed at an earlier stage $\mathrm{e}^{36,44,45}$ and so demonstrate a better prognosis, ${ }^{35,45-47}$ whereas abdominal pain ${ }^{42}$ and change in bowel habit are related to a later stage. ${ }^{36,44}$ A similar finding was noted after excluding patients who were referred after 2 weeks, indicating it is the symptom itself, rather than delays in referral, that accounts for the difference in stage and survival.

The findings of the current study regarding the interval to referral are similar to findings from an audit by Barrett et al, ${ }^{48}$ suggesting that the current study's definitions of critical time points in the patient pathway correspond to data collected from medical notes and GP questionnaires.

Thehospitalintervalwaslessvaried between red-flag and non-specific symptoms, as patients referred with colorectal-associated symptoms would be expected to undergo an endoscopic examination and(or) radiological investigation, and then await histological confirmation. The median hospital interval was marginally longer for patients referred after 3 months, who were perhaps referred through a non-urgent pathway following a period of 'watch and wait' as the suspicion of cancer was not high. This modest increase in the hospital interval is unlikely to account for the differences in stage and survival seen in this study.

\section{Implications for research and practice}

This study found that patients with redflag symptoms, particularly rectal bleeding, are presenting at an earlier stage. The first consultation with the GP provides an opportunity to refer, that, if missed, could lead to a worse stage and prognosis for patients with colorectal cancer.

This study adds to the growing area of research into delays in referring patients with suspected cancer from primary care led by Cancer Research UK, ${ }^{49}$ and should not be used as providing an acceptable period of delay before referral. As rectal bleeding is an obvious deviation from normal health, and is a target to improve public awareness of bowel cancer, patients with this symptom seek medical help sooner than those with non-specific symptoms, ${ }^{27}$ leading to an earlier stage at diagnosis. In contrast, the opportunity for an earlier diagnosis for patients with non-specific symptoms seems to be restricted because they are more likely to present at a later stage. The most recent NICE guidance on suspected cancer referral ${ }^{4}$ has the potential to improve patient outcomes because a time criterion is no longer necessary for referral. In addition, the wider availability of the 'straight to endoscopy' referral pathway may inadvertently reduce the threshold for investigation, thereby improving outcomes. Repeat analysis similar to this study with more recent data may show the benefits of these policies. 


\section{REFERENCES}

1. Coleman MP, Forman D, Bryant H, et al. Cancer survival in Australia, Canada, Denmark, Norway, Sweden, and the UK, 1995-2007 (the International Cancer Benchmarking Partnership): an analysis of population-based cancer registry data. Lancet 2011; 377(9760): 127-138.

2. Abdel-Rahman M, Stockton D, Rachet $B$, et al. What if cancer survival in Britain were the same as in Europe: how many deaths are avoidable? Br J Cancer 2009; 101(suppl 2): S115-S124.

3. Thomson CS, Forman D. Cancer survival in England and the influence of early diagnosis: what can we learn from recent EUROCARE results? $\mathrm{Br} J$ Cancer 2009; 101(suppl 2): S102-S109.

4. National Institute for Health and Care Excellence. Suspected cancer: recognition and referral. NG12. 2017. https://www.nice.org.uk/guidance/ng12 laccessed 22 May 2020).

5. Neal RD, Din NU, Hamilton W, et al. Comparison of cancer diagnostic intervals before and after implementation of NICE guidelines: analysis of data from the UK General Practice Research Database. Br J Cancer 2014; 110(3): 584-592.

6. Currie AC, Evans J, Smith NJ, et al. The impact of the two-week wait referral pathway on rectal cancer survival. Colorectal Dis 2012; 14(7): 848-853.

7. Zafar A, Mak T, Whinnie S, Chapman MA. The 2-week wait referral system does not improve 5 -year colorectal cancer survival. Colorectal Dis 2012; 14(4): e177-e180.

8. Sharpe D, Williams RN, Ubhi SS, et al. The 'two-week wait' referral pathway allows prompt treatment but does not improve outcome for patients with oesophago-gastric cancer. Eur J Surg Oncol 2010; 36(10): 977-981.

9. Ramos M, Esteva M, Cabeza E, et al. Relationship of diagnostic and therapeutic delay with survival in colorectal cancer: a review. Eur J Cancer 2007; 43(17): 2467-2478

10. Tørring ML, Murchie P, Hamilton W, et al. Evidence of advanced stage colorectal cancer with longer diagnostic intervals: a pooled analysis of seven primary care cohorts comprising 11720 patients in five countries. Br J Cancer 2017; 117(6): 888-897.

11. Macleod U, Mitchell ED, Burgess C, et al. Risk factors for delayed presentation and referral of symptomatic cancer: evidence for common cancers. $\mathrm{Br} J$ Cancer 2009; 101(suppl 2): S92-S101.

12. Astin M, Griffin T, Neal RD, et al. The diagnostic value of symptoms for colorectal cancer in primary care: a systematic review. Br J Gen Pract 2011. DOI: https://doi.org/10.3399/bjgp11X572427.

13. Hamilton W. The CAPER studies: five case-control studies aimed at identifying and quantifying the risk of cancer in symptomatic primary care patients. $\mathrm{Br} J$ Cancer 2009; 101(suppl 2): S80-S86.

14. Møller H, Gildea C, Meechan D, et al. Use of the English urgent referral pathway for suspected cancer and mortality in patients with cancer: cohort study. BMJ 2015; 351: h5102.

15. Herrett E, Gallagher AM, Bhaskaran K, et al. Data Resource Profile: Clinical Practice Research Datalink (CPRD). Int J Epidemiol 2015; 44(3): 827-836.

16. Williams T, van Staa T, Puri S, Eaton S. Recent advances in the utility and use of the General Practice Research Database as an example of a UK Primary Care Data resource. Ther Adv Drug Saf2012; 3(2): 89-99.

17. Khan NF, Perera R, Harper S, Rose PW. Adaptation and validation of the Charlson Index for Read/OXMIS coded databases. BMC Fam Pract 2010; 11: 1

18. Crooks CJ, West J, Card TR. A comparison of the recording of comorbidity in primary and secondary care by using the Charlson Index to predict short-term and long-term survival in a routine linked data cohort. BMJ Open 2015; 5(6): e007974.

19. Elliss-Brookes L, McPhail S, Ives A, et al. Routes to diagnosis for cancer: determining the patient journey using multiple routine data sets. $\mathrm{Br} J$ Cancer 2012; 107(8): 1220-1226

20. Din NU, Ukoumunne OC, Rubin G, et al. Age and gender variations in cancer diagnostic intervals in 15 cancers: analysis of data from the UK Clinical Practice Research Datalink. PLoS One 2015; 10(5): e0127717.

21. Renzi C, Lyratzopoulos G, Card T, et al. Do colorectal cancer patients diagnosed as an emergency differ from non-emergency patients in their consultation patterns and symptoms? A longitudinal data-linkage study in England. $\mathrm{Br} J$ Cancer 2016; 115(7): 866-875.

22. Weller $D$, Vedsted $P$, Rubin $G$, et al. The Aarhus statement: improving design and reporting of studies on early cancer diagnosis. Br J Cancer 2012; 106(7): $1262-1267$.
23. Lyratzopoulos G, Saunders CL, Abel GA, et al. The relative length of the patient and the primary care interval in patients with 28 common and rarer cancers. Br J Cancer 2015; 112(suppl 1): S35-S40

24. Lyratzopoulos G, Abel GA, McPhail S, et al. Measures of promptness of cancer diagnosis in primary care: secondary analysis of national audit data on patients with 18 common and rarer cancers. Br J Cancer 2013; 108(3): 686-690.

25. Bottle A, Tsang C, Parsons $C$, et al. Association between patient and general practice characteristics and unplanned first-time admissions for cancer: observational study. Br J Cancer 2012; 107(8): 1213-1219.

26. Herrett E, Thomas SL, Schoonen WM, et al. Validation and validity of diagnoses in the General Practice Research Database: a systematic review. Br J Clin Pharmacol 2010; 69(1): 4-14

27. Walter FM, Emery JD, Mendonca S, et al. Symptoms and patient factors associated with longer time to diagnosis for colorectal cancer: results from a prospective cohort study. Br J Cancer 2016; 115(5): 533-541.

28. Price SJ, Stapley SA, Shephard E, et al. Is omission of free text records a possible source of data loss and bias in Clinical Practice Research Datalink studies? A case-control study. BMJ Open 2016; 6(5): e011664.

29. Neal RD, Allgar VL, Ali N, et al. Stage, survival and delays in lung, colorectal, prostate and ovarian cancer: comparison between diagnostic routes. $\mathrm{Br} J \mathrm{Gen}$ Pract 2007; 57(536): 212-219.

30. Ramsay G, MacKay C, Nanthakumaran S, et al. Urgency of referral and its impact on outcome in patients with colorectal cancer. Colorectal Dis 2012; 14(7): e375-e377.

31. Neal RD, Tharmanathan P. France B, et al. Is increased time to diagnosis and treatment in symptomatic cancer associated with poorer outcomes? Systematic review. Br J Cancer 2015; 112(suppl 1): S92-S107.

32. Iversen LH, Antonsen S, Laurberg S, Lautrup MD. Therapeutic delay reduces survival of rectal cancer but not of colonic cancer. Br J Surg 2009; 96(10): 1183-1189.

33. Tørring ML, Frydenberg M, Hamilton W, et al. Diagnostic interval and mortality in colorectal cancer: $U$-shaped association demonstrated for three different datasets. J Clin Epidemiol 2012; 65(6): 669-678.

34. Redaniel MT, Martin RM, Ridd MJ, et al. Diagnostic intervals and its association with breast, prostate, lung and colorectal cancer survival in England: historical cohort study using the Clinical Practice Research Datalink. PLoS One 2015: 10(5): e0126608

35. Stapley S, Peters TJ, Sharp D, Hamilton W. The mortality of colorectal cancer in relation to the initial symptom at presentation to primary care and to the duration of symptoms: a cohort study using medical records. Br J Cancer 2006; 95(10): 1321-1325

36. Thompson MR, Asiimwe A, Flashman K, Tsavellas G. Is earlier referral and investigation of bowel cancer patients presenting with rectal bleeding associated with better survival? Colorectal Dis 2011; 13(11): 1242-1248.

37. Singh $\mathrm{H}$, Shu E, Demers A, et al. Trends in time to diagnosis of colon cancer and impact on clinical outcomes. Can J Gastroenterol 2012; 26(12): 877-880.

38. Van Hout AM, de Wit NJ, Rutten FH, Peeters PH. Determinants of patient's and doctor's delay in diagnosis and treatment of colorectal cancer. Eur $\mathrm{J}$ Gastroenterol Hepatol 2011; 23(11): 1056-1063

39. Terhaar sive Droste JS, Oort FA, van der Hulst RW, et al. Does delay in diagnosing colorectal cancer in symptomatic patients affect tumor stage and survival? A population-based observational study. BMC Cancer 2010; 10: 332.

40. Guzman Laura KP, Bolibar Ribas I, Alepuz MT. Impact on patient care time and tumor stage of a program for fast diagnosis and treatment of colorectal cancer. Rev Esp Engerm Dig 2011; 103(1): 13-19

41. Pruitt SL, Harzke AJ, Davidson NO, Schootman M. Do diagnostic and treatment delays for colorectal cancer increase risk of death? Cancer Causes Control 2013; 24(5): 961-977.

42. Murchie $\mathrm{P}$, Raja EA, Brewster DH, et al. Time from first presentation in primary care to treatment of symptomatic colorectal cancer: effect on disease stage and survival. Br J Cancer 2014; 111(3): 461-469.

43. Jones R, Latinovic R, Charlton J, Gulliford MC. Alarm symptoms in early diagnosis of cancer in primary care: cohort study using General Practice Research Database. BMJ 2007; 334(7602): 1040

44. Alexiusdottir KK, Möller PH, Snaebjornsson P, et al. Association of symptoms of colon cancer patients with tumor location and TNM tumor stage. Scand $J$ Gastroenterol 2012; 47(7): 795-801.

45. Korsgaard M, Pedersen L, Sørensen HT, Laurberg S. Reported symptoms, diagnostic delay and stage of colorectal cancer: a population-based study in Denmark. Colorectal Dis 2006; 8(8): 688-695. 
46. Dregan A, Møller H, Charlton J, Gulliford MC. Are alarm symptoms predictive of cancer survival?: population-based cohort study. Br J Gen Pract 2013; DOI: https://doi.org/10.3399/bjgp13X675197.

47. Ben-Ishay O, Peled Z, Othman A, et al. Clinical presentation predicts the outcome of patients with colon cancer. World J Gastrointest Surg 2013; 5(4): 104-109.
48. Barrett J, Jiwa M, Rose P, Hamilton W. Pathways to the diagnosis of colorectal cancer: an observational study in three UK cities. Fam Pract 2006; 23(1): 15-19.

49. Cancer Research UK. National Cancer Diagnosis Audit. http://www. cancerresearchuk.org/health-professional/early-diagnosis-activities/nationalcancer-diagnosis-audit (accessed 22 May 2020). 